\title{
PRODUTOS QUÍMICOS PERIGOSOS UTILIZADOS EM LABORATÓRIOS DE ENSINO - PROPOSTA E EXEMPLOS PARA INDICAÇ̃̃o DE SEUS PERIGOS NO RÓTULO
}

\author{
W. Martin Wallau* e Aline J. R. Wohlmuth Alves dos Santos \\ Centro de Ciências Químicas, Farmacêuticas e de Alimentos, Universidade Federal de Pelotas, Campus Universitário, Capão do \\ Leão S/N, CP 354, 96010-900 Pelotas - RS, Brasil
}

Recebido em 5/12/12; aceito em 19/6/13; publicado na web em 25/7/13

\begin{abstract}
DANGEROUS CHEMICAL PRODUCTS USED IN TEACHING LABORATORIES - PROPOSED SYSTEM AND EXAMPLES FOR INDICATING THEIR HAZARDS ON LABELS. Typically hundreds of different chemical products stored in small flasks which cannot accommodate labels large enough to bear all information required by the Globally Harmonised System of Classification, Labelling and Packaging of Chemicals (GHS) are used in academic laboratories. To overcome this restriction Brazilian legislation permits communication of the dangers of chemical products to trained laboratory workers/students by alternative means. Here we describe an alternative label system, developed by the German Social Accident Insurance (DGUV), which allows hazard communication to trained workers/students via a labelling system, using pictograms and highly condensed hazard statements to alert about dangerous chemical products.
\end{abstract}

Keywords: GHS; laboratory safety; labelling of dangerous chemical products.

\section{INTRODUÇÃO}

Desde 2011 a legislação brasileira exige que "o produto químico utilizado no local de trabalho deve ser classificado quanto aos perigos para a segurança e a saúde dos trabalhadores de acordo com os critérios estabelecidos pelo Sistema Globalmente Harmonizado de Classificação e Rotulagem de Produtos Químicos (GHS)" e que "a rotulagem preventiva do produto químico classificado como perigoso ... deve utilizar procedimentos definidos pelo ... (GHS)"1 atendendo "ao disposto em norma técnica oficial vigente". ${ }^{1}$ Os princípios do $\mathrm{GHS}^{2}$ que devem ser aplicados na classificação de produtos químicos e na rotulagem de produtos químicos perigosos estão estabelecidos nas partes 1 a 4 da Norma ABNT NBR $14725^{3}$ e resumidos para sua aplicação em Laboratórios de Ensino e Pesquisa em outro lugar. ${ }^{4}$

Além da identificação do fornecedor, do produto, da composição química e outras informações, a Norma ABNT NBR $14725^{3}$ exige que a periculosidade de produtos químicos seja indicada por três tópicos. Primeiro um pictograma de perigo, consistindo de um símbolo preto, sobre fundo branco, dentro de um quadrado com uma dimensão mínima de $1 \mathrm{~cm} \times 1 \mathrm{~cm}$, borda vermelha, ${ }^{5}$ apoiado num vértice, o qual deve estar de acordo com o Anexo $\mathrm{C}$ da parte 3 da Norma ABNT NBR 14725,3 como é mostrado na Tabela $1 \mathrm{~S}$ do Material Suplementar. Em segundo lugar, uma das Palavras de Advertência "Perigo" ou "Atenção", onde a primeira é usada para indicar os perigos mais graves e a segunda os de menor periculosidade. ${ }^{3}$ Em terceiro lugar uma Frase de Perigo (Frase $\mathrm{H}=$ Hazard Statement) ${ }^{2}$ descrevendo, de forma padronizada, a natureza e gravidade do risco de cada categoria de perigo, na qual o produto químico se enquadra. Estas Frases H são definidas no $\mathrm{GHS}^{2}$ e nas diversas Normas Nacionais ${ }^{3,6}$ e enumeradas na Tabela 2S do Material Suplementar. Esta indicação do perigo deve ser complementada por Frases de Precaução indicando medidas adequadas para evitar ou limitar efeitos nocivos que podem ser causados pelo produto químico perigoso. Estas Frases $\mathrm{P}(\mathrm{P}=$ Precautionary Statement) e suas atribuições às diversas categorias de perigo estão enumeradas na Norma ABNT NBR $14725 .^{3}$

$\mathrm{O}$ problema na rotulagem de produtos químicos utilizados em

*e-mail: martin_wallau@ufpel.edu.br laboratório de ensino ou pesquisa é o fato que a mesma requer trabalho intenso e tempo, para que possa atender a todas as exigências do GHS. ${ }^{1-4}$ Para diminuir estes esforços, mas mantendo as informações necessárias para comunicação dos riscos a parte 3 da Norma ABNT NBR $14725^{3}$ relata, na secção 6.10, a permissão do uso de "meios alternativos ... para fornecer ... as informações de segurança dos rótulos de produtos químicos perigosos no local de trabalho, desde que tais meios garantam uma clara comunicação de perigo e que os trabalhadores estejam devidamente treinados". ${ }^{3}$ Situação semelhante é encontrada na União Européia (UE), onde a secção 2d) do art. $1^{\circ}$ do Regulamento 1272/2008 ${ }^{6}$ dispensa a aplicação do GHS "às substâncias e misturas destinadas a actividades de investigação e desenvolvimento não colocadas no mercado, desde que sejam utilizadas em condições controladas de acordo com a legislação comunitária relativa ao ambiente e ao local de trabalho". Para assegurar a comunicação clara sobre a periculosidade de produtos químicos, a Deutsche Gesetzliche Unfallversicherung (DGUV; Associação das Cooperativas Profissionais e das Seguradoras Públicas contra Acidentes de Trabalho) desenvolveu um sistema de rotulagem simplificada publicado junto com as demais recomendações para o trabalho em laboratório (Laborrichtlinien). ${ }^{7}$

Tendo em vista que a classificação e rotulagem segundo GHS é obrigatoriedade legal ${ }^{1}$ dos responsáveis pelos laboratórios de ensino e pesquisa, um sistema de rotulagem simplificada que restringe os esforços necessários na elaboração dos rótulos a um nível razoável é um pré-requisito para evitar a rejeição do GHS no Brasil, uma vez que, também na aplicação da Norma ABNT NBR 14725 vale o ditado do Presidente do Tribunal Superior de Trabalho Ministro Carlos Alberto Reis de Paula: "A lei que não é razoável não pega". ${ }^{8}$

Assim, o intuito deste artigo é mostrar, exemplificando por meio de produtos químicos utilizados em aulas práticas das disciplinas de Química Inorgânica dos Cursos de Química da Universidade Federal de Pelotas (UFPel), a vantagem desse sistema de rotulagem simplificada, que possibilita a comunicação clara da periculosidade de produtos químicos para trabalhadores e estudantes devidamente treinados ou supervisionados, com a finalidade de prevenção e minimização dos riscos em laboratório. Atualmente este sistema de rotulagem simplificada está sendo utilizado na UFPel somente nas aulas de Química 
Inorgânica, onde todos os produtos químicos utilizados já foram classificados segundo GHS. As experiências nesta disciplina devem ser analisadas para ampliar seu uso nas demais disciplinas do Centro de Ciências Químicas, Farmacêuticas e de Alimentos.

\section{CLASSIFICAÇÃO E ROTULAGEM, SEGUNDO O GHS, DOS PRODUTOS QUÍMICOS UTILIZADOS NAS AULAS PRÁTICAS DA DISCIPLINA DE QUÍMICA INORGÂNICA DOS CURSOS DE QUÍMICA DA UFPEL}

Nas aulas práticas de Química Inorgânica nos Cursos de Química da UFPel são utilizados aproximadamente 130 substâncias diferentes dando origem a mais de 200 preparações diferentes, que envolvem substâncias puras e/ou suas soluções aquosas diluídas. As informações para a classificação das substâncias puras foram obtidas das Fichas de Informações de Segurança de Produtos Químicos (FISPQ), ${ }^{9}$ do Regulamento 1272/2008 ${ }^{6}$ da UE, da Lista de Classificação de Produtos Químicos elaborada pelo National Institute of Technology and Evaluation do Japão (NITE) ${ }^{10}$ ou do banco de dados de produtos químicos registrados pela Agência Européia das Substâncias Químicas (ECHA). ${ }^{11} \mathrm{O}$ resultado desta classificação mostrou que 90\% das substâncias puras utilizadas devem ser classificadas como produto químico perigoso em pelo menos uma das categorias de perigo definidas pelo GHS..$^{2-4}$

A classificação das preparações utilizadas, aplicando os princípios do GHS, ${ }^{2-4}$ mostrou que de um total de 230 preparações químicas utilizadas nas disciplinas de Química Inorgânica, 72\% devem ser classificadas como produto químico perigoso. Durante a classificação dos produtos químicos utilizados nas aulas práticas observou-se que para soluções aquosas simples, especialmente no caso dos perigos para saúde humana onde se usa limites de corte gerais ou específicos, ${ }^{3,4}$ a classificação segundo GHS se torna um trabalho rotineiro, deixando o maior impasse no seguimento da Norma Regulamentadora NR 26 do Ministério de Trabalho ${ }^{1}$ no que diz respeito à elaboração do rótulo.

Em caso de produtos puros, como por exemplo, solventes orgânicos, acidentalmente também utilizados em Química Inorgânica, os elementos de rotulagem podem ser diretamente obtidos da FISPQ ${ }^{9}$ ou das diversas listas de substâncias químicas classificadas. ${ }^{6,10,11} \mathrm{Um}$ exemplo para uma etiqueta confeccionada, considerando todas as exigências da Norma ABNT NBR $14725^{3}$ para uma substância pura, como acetona, é mostrada na Figura 1. Esta Figura e sua confecção revelam problemas práticos da rotulagem conforme GHS, que tornam proibitiva sua aplicação na rotulagem de produtos químicos usados no laboratório de ensino ou pesquisa.

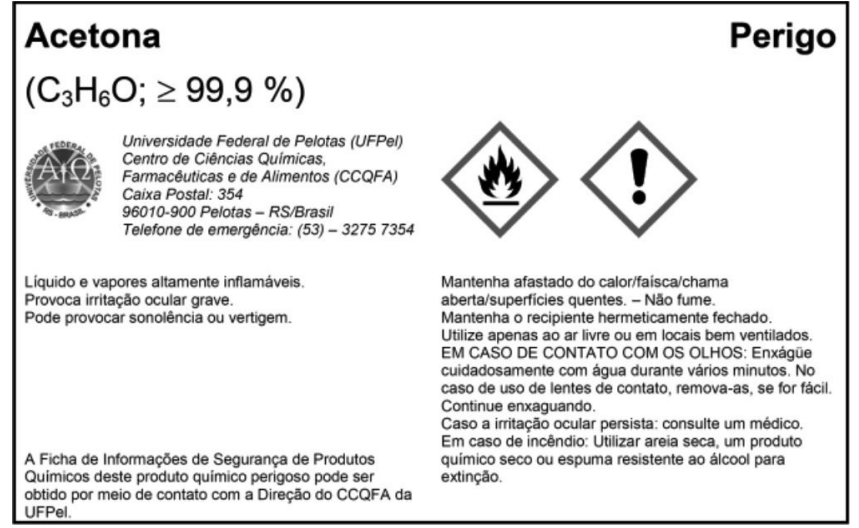

Figura 1. Rótulo para Acetona conforme ABNT NBR 14725

Primeiramente se deve considerar que nos Laboratórios de Ensino e Pesquisa se usam, frequentemente, frascos pequenos. Por exemplo, um frasco de $100 \mathrm{~mL}$ suporta apenas etiquetas com as dimensões da Figura 1, onde as letras e os pictogramas atingem o tamanho mínimo permitido pela Norma ABNT NBR 14725. ${ }^{3,12}$ Isto não somente requer uma impressão de alta qualidade, aumentando o custo na elaboração das etiquetas, mas também, como mostra a experiência pessoal de um dos autores, pode induzir colaboradores e estudantes de idade avançada a tirar os óculos (de proteção) para facilitar a leitura da etiqueta, assim contrariando sua intenção de aumentar a segurança no laboratório.

Em segundo lugar, o GHS 2 e a ABNT NBR $14725^{3}$ determinam que o número de Frases $\mathrm{P}$ nos rótulos somente pode exceder seis "se for necessário para descrever a natureza e a gravidade dos perigos". ${ }^{3}$ Porém já no caso da acetona classificada em somente três categorias de perigo, a FISPQ, ${ }^{9}$ preparada de acordo com a ABNT NBR 14725 , lista um total de 20 Frases $\mathrm{P}$ e assim, a escolha das frases $\mathrm{P}$ adequadas para o público alvo torna o processo de confecção muito demorado. Para assegurar a legibilidade de rótulos em frascos pequenos e facilitar sua confecção, a DGUV desenvolveu e testou na prática ${ }^{7}$ um sistema simplificado de rotulagem baseado no GHS.

\section{O SISTEMA DE ROTULAGEM SIMPLIFICADA DA DGUV}

Condicio sine qua non ${ }^{13}$ para aplicação deste sistema de rotulagem simplificada é sua restrição ao lugar de trabalho (laboratório) e a qualificação e instrução das pessoas (funcionários/estudantes) envolvidas na manipulação dos produtos químicos. ${ }^{3,7}$ Ainda é indispensável que seja assegurado o acesso fácil e permanente às FISPQ, permitindo que se possa obter, antes do início do trabalho, a informação adicional necessária para os pontos obscuros que não são esclarecidos pela informação condensada nos rótulos simplificados. ${ }^{3,7}$

Para simplificar a rotulagem de produtos químicos utilizados no lugar de trabalho o sistema de rotulagem proposto pela DGUV considera somente os perigos físicos ${ }^{14}$ e para saúde humana. Para a DGUV a abdicação dos perigos ao meio ambiente se justifica pelo fato que na sua alçada se espera que os produtos manipulados no laboratório sejam dispostos de maneira adequada evitando, assim, o despejo de produtos nocivos aos organismos aquáticos na rede de esgoto. No laboratório também não há necessidade de indicar o perigo para a camada de ozônio, o qual é inerente em menos de cem substâncias ${ }^{15}$ com uso restrito por regulamentações legais. ${ }^{7}$ Mesmo considerando que no caso do Brasil, nem sempre os resíduos das universidades são destinados adequadamente e que ainda carece uma boa conscientização da questão ambiental, no que se refere aos descartes de reagentes de laboratório, os autores acreditam que a indicação de perigos para o ambiente aquático é inerente aos produtos químicos utilizados em laboratório. Assim, sua indicação sobrecarregaria a etiqueta e diminuiria o espaço destinado à informação sobre os perigos físicos e à saúde humana. ${ }^{16}$

Além de abdicar categorias de perigo, o sistema proposto pela $\mathrm{DGUV}^{7}$ une diversas categorias de perigo e indica suas periculosidades no rótulo simplificado usando somente o respectivo pictograma, um apontamento de perigo e opcionalmente a palavra de advertência, como é indicada para os perigos físicos na Tabela 1. Esta tabela permite que, para cada categoria de perigo físico identificado, os elementos de rotulagem simplificada sejam encontrados a partir da Frase $\mathrm{H}$ correspondente.

O resumo das classes e categorias de perigos à saúde é feito quando não há consequências para as medidas de prevenção adotadas em laboratório ou se uma diferenciação entre as categorias necessita do fornecimento de informações específicas. Um exemplo para esta aplicação é evidenciada no caso de produtos classificados nas categorias 2 e 2A das classes "Irritação à pele" (H315 Provoca irritação à pele) e "Irritação ocular" (H319 Provoca irritação ocular grave) 
Tabela 1. Classes e categorias de perigos físicos ${ }^{14} \operatorname{com}$ os elementos de indicação, ${ }^{*}$ proposto pelo sistema da DGUV

\begin{tabular}{|c|c|c|c|}
\hline Classe (categoria) & Frase $\mathrm{H}$ & Pictograma & Apontamento \\
\hline Explosivos & H200, H201, H202, H203, H204 & & \multirow{3}{*}{ Explosivo } \\
\hline Substâncias e misturas autorreativas (A e B) & \multirow{2}{*}{$\mathrm{H} 240, \mathrm{H} 241$} & & \\
\hline Peróxidos orgânicos (A e B) & & & \\
\hline Gases inflamáveis (1) & $\mathrm{H} 220$ & & \multirow{4}{*}{ Extremamente inflamáve } \\
\hline Aerossóis (1) & $\mathrm{H} 222$ & & \\
\hline Líquidos inflamáveis (1) & $\mathrm{H} 224$ & & \\
\hline $\begin{array}{l}\text { Substancias e misturas que, em contato com a água emitem gases } \\
\text { inflamáveis }(1-3)\end{array}$ & $\mathrm{H} 260, \mathrm{H} 261$ & & \\
\hline
\end{tabular}

Líquidos inflamáveis (2)

$\mathrm{H} 225$

Altamente inflamável

\begin{tabular}{lcc}
\hline Aerossóis (2) & $\mathrm{H} 223$ \\
\hline Líquidos inflamáveis (3) & $\mathrm{H} 226$ \\
\hline Sólidos inflamáveis & $\mathrm{H} 242$ \\
\hline Substâncias e misturas autorreativas (C-F) & $\mathrm{H} 250$ \\
\hline Peróxidos orgânicos (C-F) & $\mathrm{H} 251, \mathrm{H} 252$ \\
\hline Líquidos pirofóricos & $\mathrm{H} 270$ \\
\hline Sólidos pirofóricos & $\mathrm{H} 271, \mathrm{H} 272$ \\
\hline Substâncias e misturas sujeitas a autoaquecimento & Inflama-se espontaneamente \\
\hline Gases oxidantes & Cíquidos oxidantes
\end{tabular}

Corrosivo para os metais

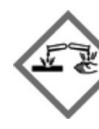

Corrosivo/Lesivo

*O sistema da DGUV sugere ainda o uso opcional da Palavra de Advertência adequada para a categoria de maior periculosidade.

e na categoria 3 (efeitos respiratórios), da classe "Toxicidade para órgãos-alvo específicos - Exposição única” (H335 Pode provocar irritação das vias respiratórias), onde os produtos destas três categorias são apontados, no sistema da DGUV, como produtos irritantes. ${ }^{7}$ Neste caso a classificação específica deve ser obtida da FISPQ e a indicação simplificada da categoria de perigo na etiqueta servirá apenas como incentivo para sua consulta. ${ }^{7}$

A Tabela 2 mostra o resumo das diversas categorias de perigos para a saúde humana e permite encontrar os respectivos elementos de indicação simplificada para uma determinada categoria a partir da respectiva Frase H. Deve se mencionar que a Tabela 2 contém a Categoria 2 da Classe "Perigo por aspiração", apontada como "Nocivo por aspiração", apesar desta categoria não estar prevista no sistema sugerido pela DGUV, ${ }^{7}$ uma vez que ela não consta no Regulamento $1272 / 2008^{6}$ da UE, sua inclusão na Tabela 2, porém, é sugerida para adaptar o sistema da DGUV7 à Norma Brasileira ABNT NBR 14725. ${ }^{3}$

O principal elemento em uma rotulagem simplificada é o pictograma, no entanto, existem diversas categorias de perigo no GHS que não exigem o uso de um pictograma. Uma análise detalhada destas categorias, porém, mostra que os requisitos mínimos exigidos e adotados durante o trabalho no laboratório ${ }^{17}$ já são suficientes para sua prevenção. Para alertar sobre os perigos desconhecidos de produtos inéditos, que necessitam medidas de proteção exaustiva, os quais podem ser eventualmente encontrados também nos laboratórios de pesquisa nas universidades, a DGUV sugere o uso de um símbolo e apontamento adicional representado por um ponto de interrogação preto sobre um fundo branco, num triangulo eqüilátero com borda vermelha, como é mostrado na Figura 2. O uso deste símbolo, não previsto no GHS, deve ser restrito aos produtos realmente inéditos e em hipótese alguma deve ser usado em rótulos de substâncias e misturas conhecidas.

\section{CONFECÇÃO DO RÓTULO SIMPLIFICADO}

Para assegurar a comunicação clara de perigo e evitar que a etiqueta seja sobrecarregada de informações, a $\mathrm{DGUV}^{7}$ recomenda que se restrinja o número de combinações Pictogramas/Apontamentos de Perigo a um máximo de três. ${ }^{7}$ Além disso, a etiqueta do produto químico utilizado no laboratório deve conter necessariamente a identificação e composição química do produto e opcionalmente a palavra de advertência e/ou eventuais informações internas como data de preparação e técnico responsável. Para um composto como acetona, classificado nas três categorias de perigo: Líquido inflamável (categoria 2), Irritação ocular (categoria 2A) e Toxicidade para órgãos-alvo específicos - exposição única (categoria 3; sistema nervoso central) identificados pelas Frases de perigo H225, H319 e H336, respectivamente, os elementos de identificação simplificada podem ser facilmente encontrados com a ajuda da Tabela 1 e da Tabela 2. Assim, a etiqueta completa mostrada na Figura 1 poderia ser substituída no laboratório pela etiqueta simplificada mostrada na Figura 3.

O sistema da rotulagem simplificada da DGUV mostra mais uma vantagem na rotulagem de produtos químicos comumente 
Tabela 2. Classes e categorias de perigo para a saúde humana com os elementos de indicação,* proposto pelo sistema da DGUV

\begin{tabular}{|c|c|c|c|}
\hline Classe (categoria) & Frase $\mathrm{H}$ & Pictograma & Apontamento \\
\hline Toxicidade aguda - oral (1 e 2) & $\mathrm{H} 300$ & & \multirow{3}{*}{ Fatal } \\
\hline Toxicidade aguda - dérmica (1 e 2) & $\mathrm{H} 310$ & & \\
\hline Toxicidade aguda - inalação (1 e 2) & H330 & & \\
\hline Toxicidade aguda - oral (3) & H301 & & \multirow{3}{*}{ Tóxico } \\
\hline Toxicidade aguda - dérmica (3) & H311 & & \\
\hline Toxicidade aguda - inalação (3) & H331 & & \\
\hline Toxicidade aguda - oral (4) & $\mathrm{H} 302$ & & \multirow{3}{*}{ Nocivo } \\
\hline Toxicidade aguda - dérmica (4) & $\mathrm{H} 312$ & & \\
\hline Toxicidade aguda - inalação (4) & H332 & & \\
\hline Corrosão/irritação à pele (1A - 1C) & H314 & & \multirow{2}{*}{ Corrosivo/Lesivo } \\
\hline Lesões oculares graves irritação ocular (1) & H318 & & \\
\hline Corrosão/irritação à pele (2) & H315 & & \multirow{3}{*}{ Irritante } \\
\hline Lesões oculares graves/irritação ocular (2A) & H319 & & \\
\hline Toxicidade para órgãos-alvo específicos - Exposição única (3 - efeitos respiratórios) & H335 & & \\
\hline Mutagenicidade em células germinativas (1A e 1B) & H340 & & \multirow{3}{*}{ Produto CMR Categoria 1} \\
\hline Carcinogenicidade (1A e 1B) & $\mathrm{H} 350$ & & \\
\hline Toxicidade à reprodução (1A e 1B) & $\mathrm{H} 360$ & & \\
\hline Mutagenicidade em células germinativas (2) & H341 & & \multirow{3}{*}{ Produto CMR Categoria 2} \\
\hline Carcinogenicidade (2) & H351 & & \\
\hline Toxicidade à reprodução (2) & H361 & & \\
\hline Sensibilização respiratória (todas) & H334 & & Alergênico se inalado \\
\hline Sensibilização à pele (todas) & H317 & & $\begin{array}{c}\text { Alergênico em contato com } \\
\text { a pele }\end{array}$ \\
\hline
\end{tabular}

Toxicidade para órgãos-alvo específicos - Exposição única (1)

Toxicidade para órgãos-alvo específicos - Exposição repetida (1)

Toxicidade para órgãos-alvo específicos - Exposição única (2)

Toxicidade para órgãos-alvo específicos - Exposição repetida (2)

Toxicidade para órgãos-alvo específicos - Exposição única (3 - efeitos ao sistema nervoso)

$\mathrm{H} 336$

Perigo por aspiração (1)

H305

336

H304

Perigo por aspiração (2)

Provoca danos aos órgãos

Narcotizante

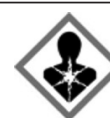

Fatal por aspiração

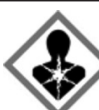

Nocivo por aspiração

*O sistema da DGUV sugere ainda o uso opcional da Palavra de Advertência adequada para a categoria de maior periculosidade.

utilizados nos laboratórios de ensino em concentrações diferentes.

Por exemplo, é muito comum o uso, na mesma aula, de soluções concentradas de hidróxido de sódio, classificadas na categoria 1A da classe Corrosão/irritação à pele, indicada pela frase de perigo H314 (Provoca queimadura severa à pele e dano aos olhos) e de soluções de baixa concentração de hidróxido de sódio como, por exemplo, 0,2
M, classificadas nas categorias 2 da classe Corrosão/irritação à pele e 2A da classe Lesões oculares graves/irritação ocular, indicadas pelas frases de perigo H315 (Provoca irritação à pele) e H319 (Provoca irritação ocular grave), respectivamente. Com a ajuda da Tabela 2 os elementos de indicação de perigo na rotulagem simplificada são facilmente encontrados e as respectivas etiquetas são mostradas na Figura 


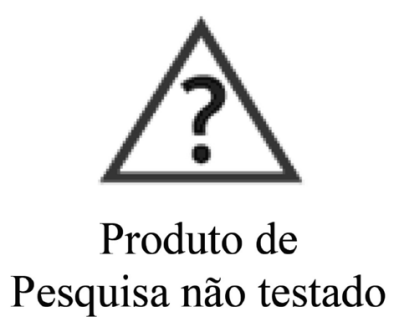

Figura 2. Símbolo alternativo para alertar sobre os perigos desconhecidos de produtos inéditos

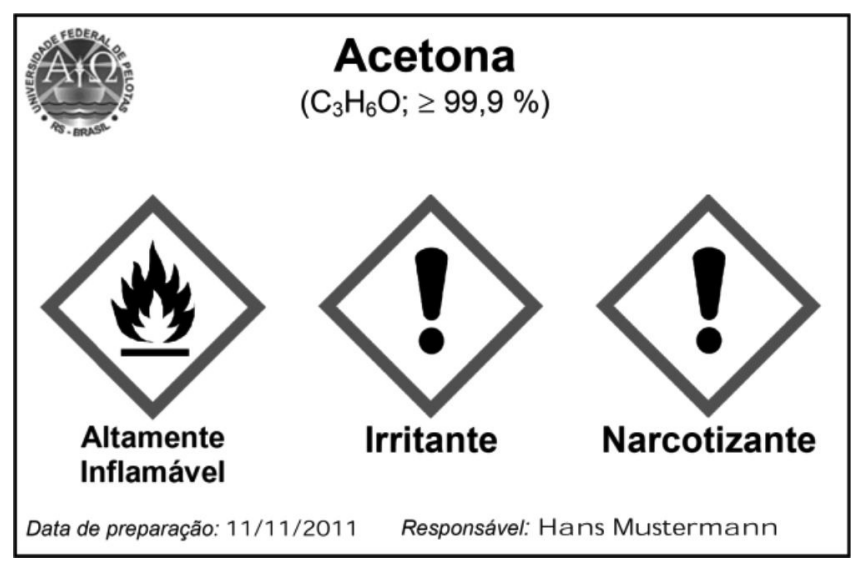

Figura 3. Rótulo simplificado da Acetona

4. Isto revela que as diferentes combinações pictograma/apontamento de perigo e as diferentes Palavras de Advertência das duas soluções servem também como um sinal, além da indicação da concentração, para distinguir as duas soluções. Assim, a rotulagem sugerida ainda ajuda a evitar que os alunos confundam as duas soluções e sejam induzidos ao erro na realização das tarefas experimentais.

Embora o número de combinações pictograma/apontamento de perigo seja limitado a três, o sistema de rotulagem simplificada é eficiente também para rotulagem de produtos químicos que possuem um maior número de potenciais riscos. Exemplarmente, a Tabela 3 mostra a classificação segundo o GHS, junto com os respectivos Pictogramas, Palavras de Advertência e Frases de perigo, bem como os elementos de Rotulagem simplificada segundo a DGUV, de uma solução aquosa $(0,1 \mathrm{M})$ de cromato de sódio utilizada nas aulas práticas das disciplinas de Química Inorgânica da UFPel.

Esta tabela evidencia que das 10 categorias de Perigos identificadas para esta solução, oito podem ser indicadas no sistema de rotulagem simplificada. Para reduzir este numero, as combinações que indicam os perigos de menor periculosidade (caracterizados pela Palavra de Advertência “Atenção") podem ser desconsideradas sem prejuízo para a segurança, em vista de que há perigos mais severos cuja prevenção exige medidas, também apropriadas, para prevenir estes perigos menos severos. Das categorias restantes deve-se escolher a indicação de corrosão à pele e da sensibilização respiratória que indicam medidas de prevenção adequadas também para as duas categorias desconsideradas. Como há classificação nas três classes para Produtos CMR Categoria 1, parece conveniente indicar no rótulo simplificado da solução de cromato de sódio os riscos de Mutagenicidade, Carcinogenicidade e Toxicidade à reprodução. Assim a rotulagem adequada desta solução utilizada em laboratório, de acordo com a DGUV, é representada na Figura 5.

Os rótulos simplificados devem ser eventualmente, complementados por uma etiqueta adicional com borda preta (ver Figura 6) que

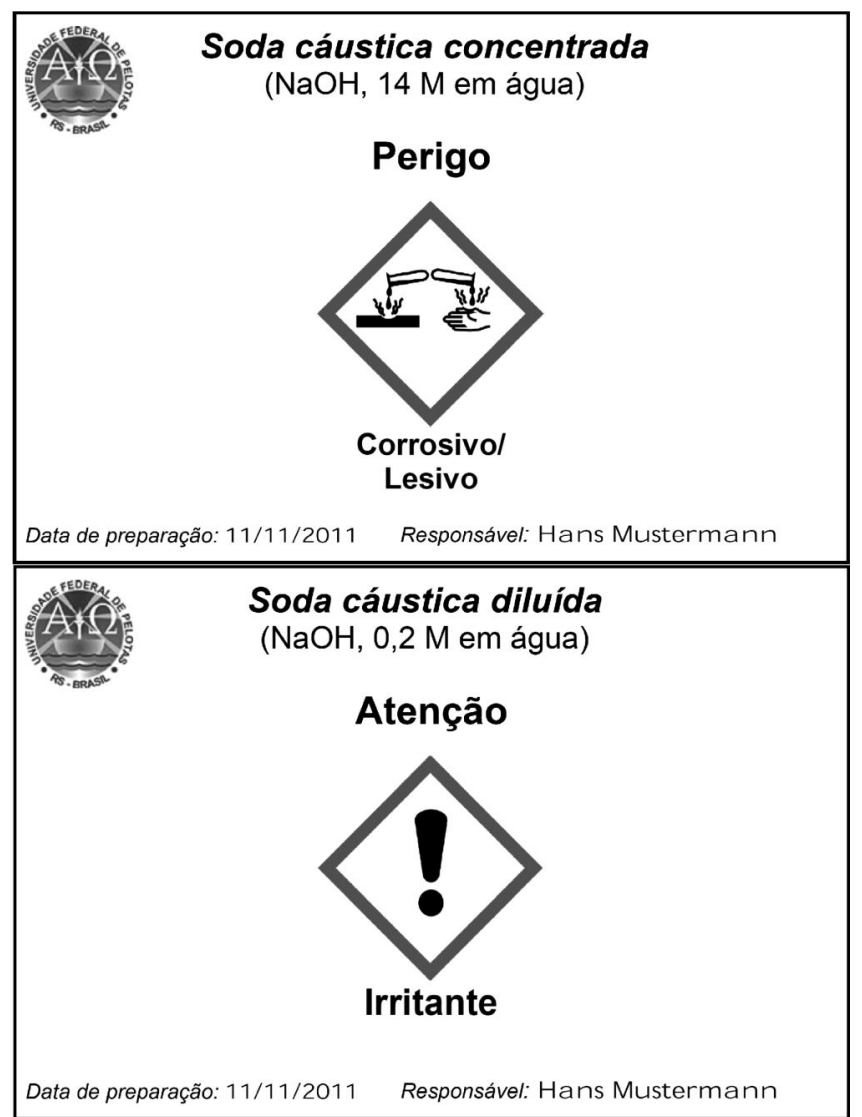

Figura 4. Etiquetas simplificadas de soluções de hidróxido de sódio em concentrações diferentes

permite, para as Categorias de Toxicidade aguda, de Produtos CMR e de Toxicidade para órgãos-alvo específicos, a indicação das vias de exposição. Potenciais perigos peculiares, como por exemplo, formação de peróxidos em éter ("Ao envelhecer, pode tornar-se perigosa"), são indicados por frases adicionais em etiquetas com borda vermelha7 (ver Figura 6).

A DGUV ${ }^{7}$ recomenda que se confeccionem etiquetas adesivas com as combinações pictograma/apontamento de perigo e das informações adicionais, que podem ser aplicadas para complementar o rótulo preenchido com as demais informações necessárias. Outro modo para facilitar a rotulagem é a criação de uma etiqueta modelo, assim, os rótulos simplificados poderiam ser confeccionados pelo preenchimento desta etiqueta modelo com a identificação e composição química do produto, seguido da Palavra de Advertência, eventuais informações internas e inserção das combinações Pictograma/ Apontamento do Perigo.

Vale lembrar que este tipo de rotulagem serve para uma pessoa adequadamente treinada e instruída, como lembrete para os perigos inerentes por ela já conhecidos. Caso ela não os conheça ou não os lembre com a devida exatidão, esta rotulagem serve como incentivo para consultar a FISPQ com o intuito de obter informações adicionais e detalhadas sobre os eventuais perigos e as medidas de prevenção adequadas. Portanto, este sistema somente pode ser implantado se o acesso permanente a estas informações é garantido.

\section{CONSIDERAÇÕES FINAIS}

A análise dos acidentes de trabalho (excetuando os ocorridos durante o trajeto trabalho - casa e vice versa), realizada pela Seguradora Pública contra Acidentes de Trabalho do Cidade-Estado 
Tabela 3. Classificação de uma solução aquosa $(0,1 \mathrm{M})$ de cromato de sódio

\begin{tabular}{lcc}
\hline Classe/Categoria de Perigo & Pictograma de Perigo/Palavra de Advertência/ & Elementos de Rotulagem simplificada \\
segundo a DGUV \\
Toxicidade aguda (inalação)/4
\end{tabular}

Corrosão à pele/1B
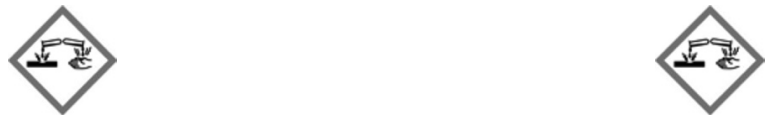

Perigo

Perigo*

H314 (Provoca queimadura severa à pele e dano aos olhos)

Sensibilização respiratória/1
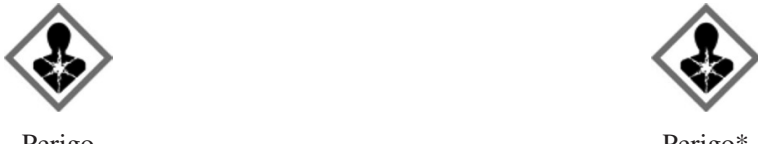

Perigo*

H334 (Quando inalado pode provocar sintomas alérgicos, de asma ou dificuldades respiratórias)

Sensibilização à pele/1

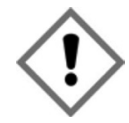

Atenção

H317 (Pode provocar reações alérgicas na pele)

Alergênico se inalado

$\begin{array}{ccc}\text { Atenção } & \text { Atenção* } \\ \text { Sensibilização à pele/1 } & \text { Alergênico em contato com a pele }\end{array}$

Mutagenicidade em células germinativas/1B

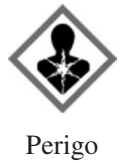

H340 (Pode provocar defeitos genéticos)

Carcinogenicidade/1B

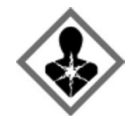

Perigo

H350 (Pode provocar câncer)

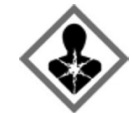

Perigo*

Produto CMR Categoria 1

Toxicidade à reprodução/1B

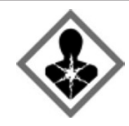

Perigo

H360 (Pode prejudicar a fertilidade ou o feto)

Toxicidade para órgãos-alvo específicos

- Exposição repetida/1

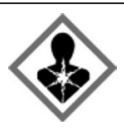

Perigo

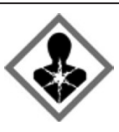

Perigo*

H372 (Provoca danos aos órgãos por exposição repetida ou prolongada) Provoca danos aos órgãos

não há

não há

H401 (Tóxico para os organismos aquáticos)

*opcional

de Berlim (Unfallkasse Berlin), no ano 2004, envolvendo estudantes das Universidades Berlinenses, revela que, embora $54 \%$ destes acidentes aconteçam durante os trabalhos práticos, a maioria deles (72\%) ocorre nos cursos de medicina, odontologia e medicina veterinária, sendo na maioria, ferimentos nos dedos sofridos durante a coleta de sangue. ${ }^{18}$ Surpreendentemente, os acidentes registrados nos laboratórios são também, na grande maioria, ocasionados por objetos perfurocortantes oriundos de quebra de vidro ou pelo uso inadequado de ferramentas afiadas. ${ }^{18}$ Pela experiência pessoal, os autores acreditam que estes dados podem refletir, também, a situação nas universidades brasileiras. Apesar disto, é equivocado pensar que a classificação e rotulagem de produtos químicos baseadas no GHS 


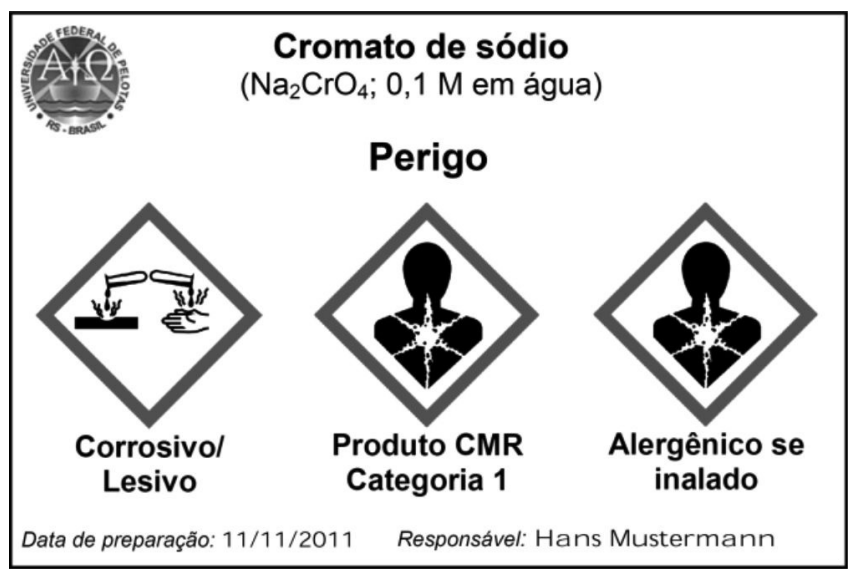

Figura 5. Rótulo de uma solução aquosa de cromato de sódio utilizada nas disciplinas de Química Inorgânica da UFPel, conforme a rotulagem simplificada da DGUV
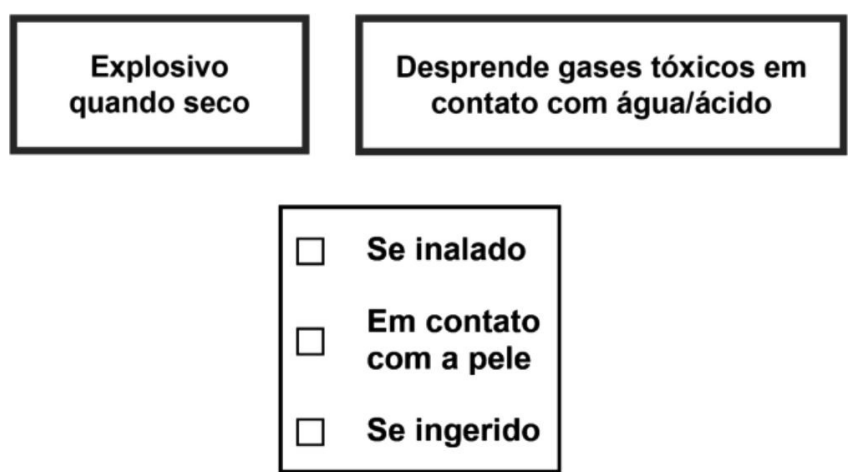

Ao envelhecer, pode tornar-se perigosa
Reage violentamente com água
Figura 6. Informações adicionais para a indicação das vias de exposição e de perigos peculiares no rótulo simplificado, segundo a $D G U V^{7}$

não aumentaria significativamente a segurança nos laboratórios de ensino, uma vez que este argumento desconsidera que a referida estatística reflete somente os perigos agudos e que a rotulagem baseada no GHS também considera a prevenção de riscos crônicos como, por exemplo, a mutagenicidade em células germinativas.

Ainda há outro argumento favorável à implantação da classificação e rotulagem baseadas no GHS, que fornece informações sobre os perigos inerentes de produtos químicos de forma universal, no cotidiano dos laboratórios de ensino e pesquisa. O GHS foi criado com o intuito de permitir a comunicação dos perigos de produtos químicos para grupos diversos, particularmente transportadores de produtos perigosos, consumidores, trabalhadores e socorristas. ${ }^{19}$ Sendo assim, os princípios do GHS necessitam ser compreendidos por pessoas de culturas diferentes, abrangendo todos os níveis de educação. Existem vários estudos que analisam a compreensão da rotulagem de produtos químicos perigosos em países tão diferentes como Reino Unido, ${ }^{20}$ Japão, ${ }^{21}$ Taiwan, ${ }^{22}$ Malásia, ${ }^{23}$ África do $S u{ }^{24} \mathrm{e}$ Zâmbia, ${ }^{25}$ por diversos grupos alvo, como estudantes de graduação, ${ }^{22}$ trabalhadores rurais, ${ }^{24}$ consumidore $\mathrm{s}^{20} \mathrm{e}$ empregados de todos os níveis, em diversos ramos econômicos..$^{21-23,25}$ Embora, devido ao fato da grande diversidade cultural e dos níveis de instrução nos grupos estudados, o grau de compreensão da informação, obtida por meio dos pictogramas de perigo, varie de estudo para estudo, no entanto, todos concordam que os fatores principais para a melhor percepção dos riscos através dos elementos de rotulagem são treinamento e educação dos grupos alvo, sugerindo que isto seja iniciado já na educação básica. ${ }^{22,24}$ Para assegurar que o conhecimento e compreensão dos elementos de comunicação de perigo sejam difundidos o mais rápido possível na sociedade, a implementação da classificação e rotulagem baseadas na linguagem universal do GHS deve ser incentivada também no Brasil, pela preparação e instrução acadêmica dos alunos, educadores, gerentes e gestores de todos os níveis.

Ressalta-se que este sistema de rotulagem simplificada não dispensa a aplicação de todas as exigências estipuladas no GHS na classificação dos produtos químicos e que mesmo com a familiaridade com as regras estipuladas, ${ }^{4}$ que parece permitir que a classificação de soluções simples possa ser rotineira, ela deve ser feita somente por pessoas qualificadas e treinadas na metodologia. No entanto, esta classificação é ineficiente caso os riscos não possam ser indicados, para o manipulador, de maneira eficiente. Mesmo que as informações contidas num rótulo atendendo a todas as exigências do GHS sejam de uma qualidade superior às informações transmitidas no rótulo simplificado, sua substituição no lugar de trabalho pela rotulagem simplificada desenvolvida e testada na prática laboratorial pela DGUV parece possível. Tendo em vista que a rotulagem simplificada somente se aplica no caso de trabalhadores instruídos e supervisionados que possuam acesso às informações contidas na FISPQ, mesmo as informações limitadas na etiqueta simplificada são suficientes para lembrar os perigos conhecidos ou incentivar a consultar à FISPQ para obter as informações necessárias para assegurar um trabalho seguro. Logo, a rotulagem simplificada de produtos químicos perigosos parece ser eficiente para informar sobre os perigos inerentes de um produto químico, de maneira clara e rápida a um técnico, previamente treinado, sobre a prevenção de doenças e acidentes, assegurando a minimização dos riscos em laboratório. Além disso, a aplicação dos princípios do GHS em laboratório parece razoável somente com o uso de rotulagem simplificada, o que permite a difusão deste tipo de informação entre os docentes, pesquisadores e estudantes de todos os cursos, cujos currículos incluam pelo menos noções básicas de química. Assim, pessoas qualificadas serão formadas e atuarão como agentes difusores da linguagem universal do GHS nos demais grupos da sociedade, ampliando o acesso à informação.

\section{MATERIAL SUPLEMENTAR}

As tabelas $1 \mathrm{~S}$ e $2 \mathrm{~S}$ encontram-se disponíveis em http://quimicanova.sbq.org.br, em arquivo pdf, com acesso livre.

\section{AGRADECIMENTOS}

Os autores agradecem o suporte financeiro de CNPq e FAPERGS.

\section{REFERÊNCIAS}

1. Ministério do Trabalho e Emprego, Norma Regulamentadora NR 26 Sinalização de Segurança, (http://portal.mte.gov.br/data/files/8A7C816 A31190C1601312A0E15B61810/nr_26.pdf, acessada em Maio 2013).

2. UNECE, Globally Harmonized System of Classification and labelling of Chemicals (GHS), $4^{\mathrm{a}}$ ed., United Nations, New York, 2011 (http://www. unece.org/trans/danger/publi/ghs/ghs_rev04/04files_e.html, acessada em Maio 2013).

3. ABNT, Produtos químicos - Informações sobre segurança e meio ambiente, partes 1 - 4, Norma Brasileira ABNT NBR 14725, Associação Brasileira de Normas Técnicas, ed.; ABNT, Rio de Janeiro, 2012. (http:// www.abntcatalogo.com.br; procurar a Norma pelo número, acessada em Maio 2013). 
4. Wallau, W.M.; dos Santos Jr., J.A; Quim. Nova 2013, 36, 607.

5. Devido a esta exigência do GHS as etiquetas devem ser impressas por impressora a cores (R. Herpich, Nachr. Chem. 2012, 60, 894).

6. União Européia, Regulamento (CE) N.o 1272/2008 do Parlamento Europeu e do Conselho de 16 de Dezembro de 2008, publicado no Jornal Oficial da União Européia de 31/12/2008, versão consolidada (http:// eur-lex.europa.eu/LexUriServ/LexUriServ.do?uri=CONSLEG:2008R1 272:20110419:PT:PDF, acessada em Maio 2013).

7. DGUV (ed.) BGI/GUV-I 850-0: Working Safely in Laboratories Basic Principles and Guidelines, 2a edição, BG RCI, Heidelberg, 2010 (http:// bgi850-0.vur.jedermann.de/index.jsp; acessada em Maio 2013).

8. C.A. Reis de Paula; em A Lei Precisa Ser Razoável, Entrevista com Daniel Pereira, VEJA, 01/05/2013, p. 72, (apud http://portal.trt22.jus. br/site/arquivos/downloads/180538_16807.pdf; acessada em Maio 2013)

9. Sigma - Aldrich, Ficha de Informações de Segurança de Produtos Químicos no 650501 Acetona; $n^{\circ}$. 216623 Cromato de sódio tetrahidratado 99 \% (http://www.sigmaaldrich.com/brazil.html; acessada em Maio 2013).

10. http://www.safe.nite.go.jp/english/ghs_index.html\#results, acessada em Maio 2013

11. http://echa.europa.eu/pt/home; acessada em Maio 2013.

12. O tamanho de letra não pode ser inferior a $1 \mathrm{~mm}$, e os pictogramas precisam ter diâmetro mínimo de $1 \mathrm{~cm}$, caso as dimensões do rotulo não permitem quadrados de $1 \mathrm{~cm} \times 1 \mathrm{~cm}$.

13. Termo legal em latim que pode ser traduzido como "sem a/o qual não pode deixar de ser". (http://pt.wikipedia.org/wiki/Sine_qua_non, acessada em Maio 2013).
14. Não se considera a classe "Gases sob Pressão", os quais geralmente são fornecidos por terceiros, ficando o fornecedor responsável pela rotulagem correta.

15. Montreal Protocol on Substances That Deplete the Ozone Layer (http:// ozone.unep.org/Publications/MP_Handbook/Section_1.1_The_Montreal_Protocol/, acessada em Maio 2013).

16. Vale lembrar que a Norma Regulamentadora NR 26 é atualmente o único documento legal que exige a aplicação do GHS no Brasil e que a mesma somente exige a classificação e indicação dos perigos para a segurança e a saúde dos trabalhadores.

17. J.C. Del Pino; V. Krüger, Segurança no Laboratório, Universidade Federal do Rio Grande do Sul, Instituto de Química, Porto Alegre, sem data (http://www.iq.ufrgs.br/aeq/html/publicacoes/matdid/livros/pdf/ Seguranca\%20laboratorio.pdf; acessada em Maio 2013).

18. Unfallkasse Berlin, Unfallgeschehen der Studierenden an Berliner Hochschulen (http://www.unfallkasse-berlin.de/content/artikel/721. html?cms_master=Print; acessada em Maio 2013).

19. Pratt, I.S.; Toxicol. Lett. 2002, 128, 5.

20. Hinks, J.; Bush, J.; Andras, P.; Garrat, J.; Pigott, G.; Kennedy, A.; PlessMulloli, T.; Sci. Total Environ. 2009, 407, 1299.

21. Hara, K.; Mori, M.; Ishitake, T.; Kitajima, H.; Sakai, K.; Nakaaki, K.; Jonai, H.; Journal of Occupational Health 2007, 49, 260.

22. Su, T.-S.; Hsu, I.-Y.; Safety Sci. 2008, 46, 1385.

23. Ta, G.C.; Mokhtar, M.B.; Mohd Mokhtar, Hj.A.B.; Ismail, A.B.; Abu Yazid, M.F. B. Hj.; Industrial Health 2010, 48, 835.

24. Rother, H.-A.; Environ. Res. 2008, 108, 419.

25. Banda, S.F.; Sichilongo, K.; Sci. Total Environ. 2006, 363, 22. 


\section{PRODUTOS QUÍMICOS PERIGOSOS UTILIZADOS EM LABORATÓRIOS DE ENSINO - PROPOSTA E EXEMPLOS PARA INDICAÇÃO DE SEUS PERIGOS NO RÓTULO}

\section{W. Martin Wallau* e Aline J. R. Wohlmuth Alves dos Santos}

Centro de Ciências Químicas, Farmacêuticas e de Alimentos, Universidade Federal de Pelotas, Campus Universitário, Capão do Leão S/N, CP 354, 96010-900 Pelotas - RS, Brasil

Tabela 1S. Pictogramas de perigo e sua atribuição às classes e categorias de perigo

\begin{tabular}{|c|c|c|c|}
\hline Pictograma & Denominação & Classes & Categorias \\
\hline & \multirow{3}{*}{ Bomba explodindo } & Explosivos & Instáveis; Divisões $1.1 ; 1.2 ; 1.3 ; 1.4$ \\
\hline & & Substâncias e misturas autorreativas & $\mathrm{A} ; \mathrm{B}$ \\
\hline & & Peróxidos orgânicos & $\mathrm{A} ; \mathrm{B}$ \\
\hline & \multirow{10}{*}{ Chama } & Gases inflamáveis & 1 \\
\hline & & Aerossóis & $1 ; 2$ \\
\hline & & Líquidos inflamáveis & $1 ; 2 ; 3$ \\
\hline & & Sólidos inflamáveis & $1 ; 2$ \\
\hline & & Substâncias e misturas autorreativas & $\mathrm{B} ; \mathrm{C} ; \mathrm{D} ; \mathrm{E} ; \mathrm{F}$ \\
\hline & & Líquidos pirofóricos & 1 \\
\hline & & Sólidos pirofóricos & 1 \\
\hline & & Substâncias e misturas sujeitas a autoaquecimento & $1 ; 2$ \\
\hline & & $\begin{array}{l}\text { Substâncias e misturas que, em contato com a água, emitem } \\
\text { gases inflamáveis }\end{array}$ & $1 ; 2 ; 3$ \\
\hline & & Peróxidos orgânicos & $\mathrm{B} ; \mathrm{C} ; \mathrm{D} ; \mathrm{E} ; \mathrm{F}$ \\
\hline & \multirow{3}{*}{ Chama sobre circulo } & Gases oxidantes & 1 \\
\hline & & Líquidos oxidantes & $1 ; 2 ; 3$ \\
\hline & & Sólidos oxidantes & $1 ; 2 ; 3$ \\
\hline & Cilindro de gás & Gases sob pressão & $\begin{array}{l}\text { Gás comprimido/Gás liquefeito/Gás liquefeito } \\
\text { refrigerado/Gás dissolvido }\end{array}$ \\
\hline & \multirow{3}{*}{ Corrosão } & Corrosivo para os metais & 1 \\
\hline & & Corrosão/irritação à pele & $1 \mathrm{~A} ; 1 \mathrm{~B} ; 1 \mathrm{C}$ \\
\hline & & Lesões oculares graves/irritação ocular & 1 \\
\hline & \multirow{3}{*}{ Crânio e ossos cruzados } & Toxicidade aguda - Oral & $1 ; 2 ; 3$ \\
\hline & & Toxicidade aguda - Dérmica & $1 ; 2 ; 3$ \\
\hline & & Toxicidade aguda - Inalação & $1 ; 2 ; 3$ \\
\hline & \multirow{8}{*}{ Ponto de exclamação } & Toxicidade aguda - Oral & 4 \\
\hline & & Toxicidade aguda - Dérmica & 4 \\
\hline & & Toxicidade aguda - Inalação & 4 \\
\hline & & Corrosão/irritação à pele & 2 \\
\hline & & Lesões oculares graves/irritação ocular & $2 \mathrm{~A}$ \\
\hline & & Sensibilização à pele & $1 \mathrm{~A} ; 1 \mathrm{~B}$ \\
\hline & & Toxicidade para órgãos - alvo específicos - Exposição única & 3 \\
\hline & & Perigoso à camada de ozônio & 1 \\
\hline & \multirow{7}{*}{ Perigoso à saúde } & Sensibilização respiratória & $1 \mathrm{~A} ; 1 \mathrm{~B}$ \\
\hline & & Mutagenicidade em células germinativas & $1 \mathrm{~A} ; 1 \mathrm{~B} ; 2$ \\
\hline & & Carcinogenicidade & $1 \mathrm{~A} ; 1 \mathrm{~B} ; 2$ \\
\hline & & Toxicidade à reprodução & $1 \mathrm{~A} ; 1 \mathrm{~B} ; 2$ \\
\hline & & \multirow{3}{*}{$\begin{array}{c}\text { Toxicidade para órgãos - alvo específicos - Exposição única } \\
\text { Toxicidade para órgãos - alvo específicos - Exposição } \\
\text { repetida } \\
\text { Perigo por aspiração }\end{array}$} & $1 ; 2$ \\
\hline & & & $1 ; 2$ \\
\hline & & & $1 ; 2$ \\
\hline & \multirow{3}{*}{ Meio ambiente } & Perigoso ao ambiente aquático - Agudo & 1 \\
\hline & & & \\
\hline & & Perigoso ao ambiente aquático - Agudo & $1 ; 2$ \\
\hline
\end{tabular}

*e-mail: martin_wallau@ufpel.edu.br 
Tabela 2S. Lista das Frases de Perigo previsto na Norma ABNT NBR 14725

\begin{tabular}{ll}
\hline & \multicolumn{1}{c}{ Explosivos } \\
\hline H200 & Explosivo instável. \\
H201 & Explosivo; perigo de explosão em massa. \\
H202 & Explosivo, perigo grave de projeção. \\
H203 & Explosivo; perigo de incêndio, deslocamento de ar ou projeções. \\
H204 & Perigo de incêndio ou projeções. \\
H205 & Perigo de explosão em massa em caso de incêndio. \\
\hline & \\
\hline H220 & Gás extremamente inflamável. \\
H221 & Gás inflamável. \\
H222 & Aerossol extremamente inflamável. \\
H223 & Aerossol inflamável. \\
H224 & Líquido e vapores extremamente inflamáveis. \\
H225 & Líquido e vapores altamente inflamáveis. \\
H226 & Líquido e vapores inflamáveis. \\
H227 & Líquido combustível. \\
H228 & Sólido inflamável. \\
H229 & Recipiente pressurizado: pode romper se aquecido. \\
H230 & Pode reagir explosivamente mesmo na ausência de ar. \\
H231 & Pode reagir explosivamente mesmo na ausência de ar em pressão \\
& e/ou temperatura elevada(s). \\
\hline
\end{tabular}

\begin{tabular}{ll}
\hline \multicolumn{1}{c}{ Substancias e misturas autorreativas } \\
\hline H240 & Pode explodir sob ação do calor. \\
H241 & Pode explodir ou incendiar sob a ação do calor. \\
H242 & Pode incendiar sob a ação do calor. \\
\hline
\end{tabular}

Pirofóricos/sujeitas a autoaquecimento/emitem gases inflamáveis

H250 Inflama-se espontaneamente em contacto com o ar.

H251 Sujeito a autoaquecimento, pode se inflamar.

H252 Sujeito a autoaquecimento em grandes quantidades, pode se inflamar.

H260 Em contacto com a água desprende gases inflamáveis que se podem inflamar-se espontaneamente.

H261 Em contacto com a água desprende gases inflamáveis.

\begin{tabular}{ll}
\hline \multicolumn{1}{c}{ Oxidantes } \\
\hline H270 & Pode provocar ou agravar um incêndio; oxidante. \\
H271 & Pode provocar incêndio ou explosão; muito comburente. \\
H272 & Pode agravar um incêndio; comburente. \\
\hline
\end{tabular}

\section{Gases sob pressão}

H280 Contém gás sob pressão: pode explodir sob a ação do calor.

H281 Contém gás refrigerado: pode causar queimaduras ou lesões criogénicas.

\begin{tabular}{ll}
\hline & \multicolumn{1}{c}{ Corrosivo para os metais } \\
\hline H290 & Pode ser corrosivo para os metais. \\
\hline \multicolumn{1}{c}{ Toxicidade aguda (ingestão) } \\
\hline H300 & Fatal se ingerido. \\
H301 & Tóxico se ingerido. \\
H302 & Nocivo se ingerido. \\
\hline
\end{tabular}

\section{Toxicidade aguda (ingestão)}

H303 Pode ser nocivo se ingerido.

H304 Pode ser fatal se ingerido e penetrar nas vias respiratórias.

H305 Pode ser nocivo se ingerido e penetrar nas vias respiratórias.

\section{Toxicidade aguda (dérmica)}

H310 Fatal em contato com a pele.

H311 Tóxico em contato com a pele.

H312 Nocivo em contato com a pele.

H313 Pode ser nocivo em contato com a pele.

\begin{tabular}{ll}
\hline \multicolumn{1}{c}{ Corrosão/irritação à pele } \\
\hline H314 & Provoca queimadura severa à pele e dano aos olhos. \\
H315 & Provoca irritação à pele. \\
H316 & Provoca irritação moderada à pele. \\
H317 & Pode provocar reações alérgicas na pele. \\
\hline & \multicolumn{1}{c}{ Lesões oculares graves/irritação ocular } \\
\hline H318 & Provoca lesões oculares graves. \\
H319 & Provoca irritação ocular grave. \\
H320 & Provoca irritação ocular. \\
\hline & \multicolumn{1}{c}{ Toxicidade aguda (inalação) } \\
\hline H330 & Fatal se inalado. \\
H331 & Tóxico se inalado. \\
H332 & Nocivo se inalado. \\
H333 & Pode ser nocivo se inalado. \\
H334 & Quando inalado, pode provocar sintomas alérgicos, de asma ou \\
dificuldades respiratórias. \\
H335 & Pode provocar irritação das vias respiratórias. \\
H336 & Pode provocar sonolência ou vertigens. \\
\hline
\end{tabular}
Mutagenicidade em células germinativas

H340 Pode provocar defeitos genéticos (indicar a via de exposição, se for conclusivamente comprovado que nenhuma outra via de exposição provoca o dano)

H341 Suspeito de provocar defeitos genéticos (descrever a via de exposição, se for conclusivamente comprovado que nenhuma outra via de exposição provoca o dano)

\section{Carcinogenicidade}

H350 Pode provocar câncer (indicar a via de exposição, se for conclusivamente comprovado que nenhuma outra via de exposição provoca o dano)

H351 Suspeito de provocar câncer (indicar a via de exposição, se for conclusivamente comprovado que nenhuma outra via de exposição provoca o dano)

\section{Toxicidade à reprodução}

H360 Pode prejudicar a fertilidade ou o feto (indicar o efeito específico, se conhecido) se ... (indicar a via de exposição, se for conclusivamente comprovado que nenhuma outra via de exposição provoca o dano)

H361 Suspeita-se que prejudique a fertilidade ou o feto (indicar o efeito específico, se conhecido) se ... (indicar a via de exposição, se for conclusivamente comprovado que nenhuma outra via de exposição provoca o dano).

H362 Pode ser nocivo para as crianças alimentadas com leite materno 
Tabela 2S. continuação

\section{Toxicidade para órgãos-alvo específicos}

H370 Provoca danos aos órgãos (indicar todos os órgãos afetados, se conhecidos) se ... (indicar o efeito específico, se conhecido) se ... (indicar a via de exposição, se for conclusivamente comprovado que nenhuma outra via de exposição provoca o dano)

H371 Pode provocar danos aos órgãos (indicar todos os órgãos afetados, se conhecidos) se ... (indicar a via de exposição, se for conclusivamente comprovado que nenhuma outra via de exposição provoca o dano)

H372 Provoca danos aos órgãos (indicar todos os órgãos afetados, se conhecidos) por exposição repetida ou prolongada (indicar a via de exposição, se for conclusivamente comprovado que nenhuma outra via de exposição provoca o dano)

H373 Pode provocar danos aos órgãos (indicar todos os órgãos afetados, se conhecidos) por exposição repetida ou prolongada (indicar a via de exposição, se for conclusivamente comprovado que nenhuma outra via de exposição provoca o dano)

\section{Perigoso ao meio ambiente}

H400 Muito tóxico para os organismos aquáticos.

H401 Tóxico para organismos aquáticos.

H402 Nocivo para organismos aquáticos.

H410 Muito tóxico para os organismos aquáticos, com efeitos prolongados.

H411 Tóxico para os organismos aquáticos, com efeitos prolongados.

H412 Nocivo para os organismos aquáticos com efeitos prolongados.

H413 Pode provocar efeitos nocivos prolongados para os organismos aquáticos.

H420 Provoca danos à saúde pública e ao meio ambiente pela destruição da camada de ozônio. 